\title{
The Influence of Water on the Performance of Organic Electrochemical Transistors
}

\author{
Achilleas Savva, ${ }^{\dagger}$ Camila Cendra, ${ }^{\ddagger}$ Andrea Giugni, ${ }^{\#}$ Bruno Torre, ${ }^{\#}$ Jokubas Surgailis, ${ }^{\dagger}$ David Ohayon, ${ }^{\dagger}$ \\ Alexander Giovannitti, ${ }^{\S}$ Iain McCulloch, ${ }^{\S, \|}$ Enzo Di Fabrizio, ${ }^{\#}$ Alberto Salleo, ${ }^{\ddagger}$ Jonathan Rivnay ${ }^{\nabla}$ and \\ Sahika Inal ${ }^{\dagger *}$
}

${ }^{\dagger}$ Biological and Environmental Science and Engineering, King Abdullah University of Science and Technology (KAUST), Thuwal 23955-6900, Kingdom of Saudi Arabia

${ }^{\ddagger}$ Department of Materials Science and Engineering, Stanford University, Stanford, California 94305, United States

\# SMILEs laboratory, Physical Science and Engineering (PSE), KAUST, Thuwal 23955-6900, Kingdom of Saudi Arabia

$\S$ Department of Chemistry, Imperial College London, SW72AZ, UK

" PSE, KAUST Solar Center (KSC), KAUST, Thuwal 23955-6900, Kingdom of Saudi Arabia

${ }^{\nabla}$ Department of Biomedical Engineering, Northwestern University, Evanston, Illinois, 60208, United States

\begin{abstract}
Organic electrochemical transistors (OECTs) comprised of organic mixed conductors can operate in aqueous, biological media and translate low magnitude ionic fluctuations of biological origin into measurable electrical signals. The growing technological interest in these bio-transducers makes the fundamental understanding of ion-to-electron coupling extremely important for the design of new materials and devices. One crucial aspect in this process that has been so far disregarded is the water taken up by the film during device operation and its effects on device performance. Here, using a series of the same electrolyte with varying ion concentrations, we quantify the amount of water that is incorporated into a hydrophilic p-type organic semiconductor film alongside the dopant anions and investigate structural and morphological changes occurring in the film upon electrochemical doping. We show that infiltration of the hydrated dopant ions into the film irreversibly changes the polymer structure and negatively impacts the efficiency, reversibility and speed of charge generation. When less water is injected into the channel, OECTs exhibit higher transconductance and faster switching speeds. Although swelling is commonly suggested to be a necessity for efficient ion-to-electron transduction, this work uncovers the negative impact of a swollen channel material on the performance of accumulation mode OECTs and lays the foundation for future materials design.
\end{abstract}

\section{INTRODUCTION}

Organic semiconductors revolutionized the way we look at electronic materials due to their molecularly tunable electrical properties in combination with their soft mechanical properties. Importantly, their ability to conduct ionic in addition to electronic charges has attracted broad interest, particularly for the field of bioelectronics. ${ }^{1}$ In biological systems, signal transmission involves ionic fluxes that arise due to local transport of ions or charged neurotransmitters across cell membranes. ${ }^{2}$ In order to transduce these signals, organic semiconductors that accommodate mixed conduction, i.e. organic mixed conductors, have shown great potential. ${ }^{3}$ To this end, electronic devices based on organic semiconductors have led to state of the art biosensors including implantable electrode arrays for measuring cortical neural signals, ${ }^{4}$ impedance-based cell monitoring devices, ${ }^{5}$ as well as metabolite sensors. ${ }^{6,7}$ Among these devices, organic electrochemical transistors (OECTs) that operate in aqueous electrolytes are particularly interesting for transducing and amplifying low amplitude ionic fluctuations of biological origin. ${ }^{8}$

In an OECT, the application of a gate bias drives ions into the channel that electrostatically compensate the electronic charges provided by the source electrode. The channel is made of an organic mixed conductor that can undergo reversible changes in its doping state by exchanging ions with an aqueous electrolyte, i.e., the biological media. A typical material for OECTs is the p-type semiconducting polymer poly(3,4-ethylenedioxythiophene) doped with poly(styrenesulfonate) (PEDOT:PSS). ${ }^{9}$ While such conducting polymer-based OECTs operate in depletion mode, it is also possible to operate OECTs in accumulation mode if the channel is made of a semiconducting polymer permeable to ions. ${ }^{10}$ These polymers consist of a conjugated backbone modified with side chains that are either charged (known as conjugated polyelectrolytes) or carry nonionic but polar chemical units (e.g. ethylene glycol). ${ }^{11}$ The rationale of the side chain modification is to promote interactions of the rather hydrophobic backbone with water, enabling ion penetration/transport within the channel. With tailored molecular designs, accumulation mode materials can be further customized based on the need of the applications, e.g., enable specific associations with proteins/cells or adhere stronger to surfaces 
that they are cast on. ${ }^{12} \mathrm{~A}$ recent example for such polymers is the p-type poly(2-(3,3'-bis(2-(2-(2-methoxyethoxy)ethoxy)ethoxy)[2,2'-bithiophen]-5-yl)thieno[3,2-b] thiophene), $\mathrm{p}(\mathrm{g} 2 \mathrm{~T}-\mathrm{TT})$, which has shown superior OECT performance compared to state-of-theart PEDOT:PSS based devices. ${ }^{13}$ Regardless of the mode of operation, the identifying characteristic of OECTs is the volumetric interactions of the electrolyte ions with the channel. ${ }^{14}$ The extent of these interactions governs the transconductance of the device, i.e., the transduction of an ionic flux into an electronic current. ${ }^{1,15}$

While a number of studies have investigated electrochemical processes in PEDOT:PSS and the depletion mode OECTs, ${ }^{16-18}$ the electrochemical phenomena at the aqueous interface of undoped, single component semiconducting polymer films remain rather unexplored. However, ion injection process and mixed transport properties of these semiconducting polymers are expected to be inherently different compared with PEDOT:PSS: the latter swells almost double its thickness/volume when immersed in water due to the hydrophilic polyanion phase (i.e. PSS) and cation transport takes place in this swollen phase, a region (almost) physically separated from PEDOT. ${ }^{19}$ Semiconducting polymers with grafted hydrophilic side chains, on the other hand, do not contain such a bulky ionic phase. Therefore, our gap in knowledge, firstly, resides in understanding the route of ions inside these films. Secondly, little is known about how the polymeric network is affected by the encounter with dopant ions. In this context, Guardado et al. has revealed changes in lattice spacing and crystallite orientation in the bulk of the semiconducting polymer poly(3-hexylthiophene) (P3HT) induced upon electrochemical doping by an ionic liquid. ${ }^{20}$ The dopant ions are dragged into the crystalline regions when a low frequency, high amplitude voltage bias is applied across the polymer film. Such intercalation of dopant molecules in crystallites has also been observed when P3HT was chemically doped with tetrafluoro-tetracyanoquinodimethane, leading to more oligomer-like chains with low hole mobility. ${ }^{21}$ Giridharagopal et al., on the other hand, showed that amorphous regions of a P3HT film undergoes sub-nanometer swelling as dopant anions from an aqueous electrolyte penetrate into the film. ${ }^{22}$ These studies evidence a significant, voltage dependent, distortion of the polymer lattice/nano-morphology upon ion-induced doping, which are likely to have consequences on the charge transport as well as on the operation of OECTs. Finally, during the operation OECTs in aqueous electrolytes, in addition to dopant ions, the polymer film also interacts with water. The electrolyte ions are hydrated, ${ }^{23}$ and, as such, their drift in and out of the polymeric channel might/can involve a significant amount of water molecules. In fact, we have recently shown that when exposed to de-doping potentials, PEDOT:PSS films undergo significant volumetric expansion not only due to uptake of cations but also of water, and they shrink as water and cations are ejected from the film. ${ }^{19}$ A recent study of Ginger and coworkers demonstrated the effect of the hydration state of dopant anions on the electrochemical doping of P3HT. ${ }^{24}$ The ions with high hydration numbers in water allow water to enter the hydrophobic film, which slows down the transistors and increases the threshold voltage. In contrast to $\mathrm{P} 3 \mathrm{HT}$, the aforementioned hydrophilic semiconducting polymers can swell with water, which is the feature that primarily renders them suitable for OECTs. ${ }^{13}$ However, due to the single component nature of these polymers, water uptake during doping should have implications on the microstructure and transport properties, as well as on the output characteristics of OECTs comprising these polymers. Monitoring such in-operando bulk structural and morphological state of the film and linking it to the extent of swelling and the device performance can give us important guidelines to design mixed conductors showing favorable ion-polymer interactions, i.e. high transconductance in OECTs.

In this study, we investigate the impact of water on the electrochemical behavior of the top OECT performer p-type semiconductor, $\mathrm{p}(\mathrm{g} 2 \mathrm{~T}-\mathrm{TT})$, in aqueous $\mathrm{NaCl}$ solutions of varying salt concentrations. Since the hydration of the dopant anion, i.e. $\mathrm{Cl}^{-}$, gradually increases with a decrease in electrolyte concentration, ${ }^{25}$ we are able to modulate the hydration of the film without changing the nature of the dopant. Doping the films in these electrolytes allows us to control the extent of water/polymer interactions and to monitor the influence of channel hydration on OECT operation. By using electrochemical quartz crystal microbalance with dissipation monitoring (EQCM-D), we find that a significant amount of water is incorporated into the film during electrochemical doping, increasing with a decrease in electrolyte concentration. The water taken up by the film has two main adverse effects: 1) it limits the speed of electrochemical switching and, 2) impairs the reversibility of the doping process. We perform ex-situ grazing incidence wide angle X-ray scattering (GIWAXS) studies and in-situ Raman spectroscopy in order to understand the consequences of hydration on the polymer microstructure. The rather drastic and permanent lamellar expansion upon doping confirms that anions can infiltrate into the crystallites, while water accumulates between the glycol side chains and mainly in the amorphous regions of the film. Excess water uptake by these regions irreversibly disrupts the overall structural order. The net result is a decrease in hole mobility. Consequently, with an increase in the hydration of the OECT channel, we measure a reduction in the transconductance. By controlling the degree of swelling of the channel - optimized to enable facile ion penetration, yet minimal deterioration of the film structure - the transconductance is maximized alongside with an improvement of switching speeds of OECTs. These results show that while swelling of the mixed conductor channel is needed to enable OECT operation, it must be carefully balanced to minimize adverse structural changes in the film.

\section{EXPERIMENTAL}

\section{Materials}

$\mathrm{p}(\mathrm{g} 2 \mathrm{~T}-\mathrm{TT})$ was synthesized as described previously. ${ }^{13}$ All the other chemicals were purchased from Sigma Aldrich and used as received.

\section{OECT Fabrication}

The devices were fabricated according to the parylene-C lift-off method reported previously. ${ }^{26}$ Standard microscope glass slides were cleaned via sonication in an acetone and isopropyl alcohol solution and dried with $\mathrm{N}_{2}$. Connection pads and interconnects were deposited through a lift-off process using photolithographic patterning of positive photoresist (S1813). A subsequent metal deposition via sputtering of $\mathrm{Cr}(10 \mathrm{~nm})$ and of $\mathrm{Au}(120 \mathrm{~nm})$ and metal lift-off using acetone defines the Au lines. A first layer of parylene $\mathrm{C}$ 
$(2 \mu \mathrm{m})$, deposited together with a small amount of 3-(trimethoxysilyl)propyl methacrylate (A-174 Silane) to enhance adhesion, acts as an insulator to prevent disturbing capacitive effects at the metal liquid interface. Subsequently, an antiadhesive layer was spin coated using a dilution of industrial cleaner ( $2 \mathrm{wt} \%$, Micro- 90$)$ and a second parylene-C sacrificial layer $(2 \mu \mathrm{m})$ is deposited. To define the contact pads and the channel of the OECT, a second photolithographic patterning step using a thick positive photoresist $(5 \mu \mathrm{m}$, AZ9260) and AZ developer is used to protect the parylene-C layers from a subsequent plasma reactive ion etching step. All the polymer solutions were prepared in chloroform at $5 \mathrm{mg} / \mathrm{mL}$ (if not mentioned otherwise) and spin coated from a glass fiber filter with $0.45 \mu \mathrm{m}$ of pore diameter. Peeling of the parylene-C sacrificial layer defines the channel dimensions. The thickness of the channels was measured using a DEKTAK 150 stylus profilometer.

\section{OECT Characterization}

OECTs were characterized using a dual-channel source-meter unit (NI-PXI) with custom-written control code in LabVIEW. All measurements were performed using an $\mathrm{Ag} / \mathrm{AgCl}$ pellet $(\mathrm{D}=2 \mathrm{~mm} \times \mathrm{H}=2 \mathrm{~mm}$-Warner instruments $)$ as the gate electrode. The electrolytes in water were contained in a PDMS well on top of the OECTs and the electrolyte volume was constant at $80 \mu \mathrm{L}$ for all measurements. The DC response time of the OECTs was estimated using an exponential fit to the drain current recorded after applying a $5 \mathrm{~ms}$ long doping pulse at the gate electrode. The AC response time of the OECTs was calculated via bandwidth measurements, using the 3-dB cut-off frequency equivalent to 0.707 times of the peak of transconductance, also known as the half power point. Mobility $\left(\mu_{\mathrm{OECT}}\right)$ was determined by applying a constant drain bias to the channel and a sinusoidal voltage pulse at the gate electrode $\left(\Delta \mathrm{V}_{\mathrm{G}}=10 \mathrm{mV}\right)$ with a pre-set offset $\left(\mathrm{V}_{\mathrm{G}}\right.$, offset $)$ and at varying frequencies. The frequency domain relation between the measured gate current $\left(\Delta \mathrm{I}_{\mathrm{G}}\right)$ and drain current $\left(\Delta \mathrm{I}_{\mathrm{D}}\right)$ is: ${ }^{27}$

eq. 1: $\quad \Delta I_{G}(f)=2 \pi f \tau_{e} \Delta I_{D}(f)$

Matching the gate current and drain current derived impedance yields hole/electron transit time in the channel $\left(\tau_{\mathrm{e}}\right)$, as detailed by Rivnay et al. ${ }^{28}$ Using the $\tau_{\mathrm{e}}$, the channel length $(L)$, and the applied drain bias $\left(V_{\mathrm{D}}\right), \mu_{\mathrm{OECT}}$ can be estimated:

eq. 2: $\quad \mu_{\mathrm{OECT}}=\frac{L^{2}}{\tau_{\mathrm{e}} V_{D}}$

\section{Swelling Analysis}

We performed EQCM-D measurements using a Q-sense analyzer (QE401, Biolin Scientific). Swelling measurements were performed as follows. First, we recorded the QCM-D response of the bare Au sensors in the air, followed by the injection of the aqueous $\mathrm{NaCl}$ solutions into the chamber. This resulted in large shifts in $f$ and $D$, due to the density differences between the two media, which must be excluded from the swelling percentage calculation. The measurements were then stopped, the sensors were removed and $\mathrm{p}(\mathrm{g} 2 \mathrm{~T}-$ TT) layers were spin coated directly on the same sensor from a chloroform solution $(5 \mathrm{mg} / \mathrm{mL})$ at $1 \mathrm{krpm}$. We then compared the absolute difference in $f$ for multiple overtones between the bare sensor and the Ti/Au/p(g2T-TT) coated sensors, both in air and in the corresponding $\mathrm{NaCl}$ solutions, by using the function "stitched data" of Q-soft software. This function compares the selected datasets based on the raw frequencies measured and excludes the effect of the different densities between the two mediums (Figure $\mathrm{S} 1)$. Thus, the difference of the $f$ values of the stitched data is directly analogous to the thickness of the polymer in both media, which is calculated by using the Sauerbrey equation below (eq. 3)

\section{EQCM-D Analysis}

EQCM-D measurements were performed using Autolab PGstat128N potentiostat coupled with Q-sense electrochemistry module. The three-electrode setup was comprised of $\mathrm{Ag} / \mathrm{AgCl}$ reference, Pt counter and Au/polymer EQCM-D sensor as the working electrode. The physical modelling of the two measured parameters, the $f$ and $D$, is related to the viscoelastic properties of the film. On the one hand, a rigid film shows zero $D$ as there are theoretically no energy losses (no viscoelasticity) and Sauerbrey equation can be used to quantify the mass $(m)$, using only one overtone as described in equation 3 :

eq. 3: $\quad \Delta \mathrm{m}=\frac{-17.7}{\mathrm{n}} \Delta \mathrm{f}_{\mathrm{n}}$

On the other hand, a thicker and/or softer film, does not follow the motion of the crystal and leads to energy losses during the oscillation. We approximate thicker and/or soft films to behave like a Kelvin-Voigt element, which means that they exhibit both viscous and elastic characteristics acting in parallel (viscoelastic). A Kelvin-Voigt element has a complex shear modulus as described in equation 4:

eq. 4: $\quad G^{*}=\mu+2 \pi i f \eta$

where $G^{*}$ is the complex shear modulus, $\mu$ is elasticity $\left(\mathrm{kgm}^{-1} \mathrm{~s}^{-2}\right), \eta$ is viscosity $\left(\mathrm{kgm}^{-1} \mathrm{~s}^{-1}\right)$ and $f$ is the frequency.

To calculate the mass changes of a thick, viscoelastic film, complex shear modulus was analyzed and fitted using at least three frequency and dissipation of energy overtones. Q-Tools and D-find software were used for the modeling and data analysis. Since p(g2T-TT) films are becoming soft and uptake a significant amount of water under doping potentials, we used the Kelvin-Voigt viscoelastic (VSE) model to fit the data. To quantify the mass correctly, we used the $f$ and $D$ data of three different overtones $\left(5^{\text {th }}, 7^{\text {th }}\right.$ and $9^{\text {th }}$. The good quality of the fits guaranteed the accurate mass calculation accumulated within the films upon applied potentials. 
To convert the recorded mass into number of $\mathrm{Cl}^{-}$ions, we divided the recorded mass values with the weight of pure $\mathrm{Cl}^{-}$atoms $\left(5.88725^{*} 10^{-23} \mathrm{gr} /\right.$ atoms $)$.

\section{Electrochemical analysis}

Electrochemical impedance spectroscopy (EIS) was performed from $10 \mathrm{kHz}$ to $0.1 \mathrm{~Hz}$ in the EQCM-D electrochemical cell. The measurements were performed either at $V_{\mathrm{oc}}$ or at a DC offset potential (doping) with an AC amplitude of $10 \mathrm{mV}$. The capacitancefrequency plots of each film were constructed by using the complex impedance formula as described in equation 5:

eq. 5 :

$$
Z=\sqrt{R^{2}+\frac{1}{\omega^{2} C^{2}}}
$$

The diffusion coefficient for the four systems under study was calculated based on the Cottrell equation and using the raw data obtained from the chronoamperometry, current vs time.

eq. 6: $\quad I=\frac{n F A c_{j}^{0} \sqrt{D_{j}}}{\sqrt{\pi t}}$

where $I$ is current, $n$ is the number of electronic charges (to oxidize one molecule of the analyte (e.g. p(g2T-TT)=1), $F$ is the Faraday constant $(96485 \mathrm{C} / \mathrm{mol}), A$ is the area of the electrode $\left(0.7854 \mathrm{~cm}^{2}\right), c_{\mathrm{j}}$ is the concentration of the electrolyte, $D_{\mathrm{j}}$ is the diffusion coefficient of the dopant ions in the electrolyte and, finally, $t$ is the time.

\section{X-ray characterization}

Films for ex-situ X-ray scattering were prepared inside a $\mathrm{N}_{2}$ glovebox $\left(<1 \mathrm{ppm} \mathrm{O}_{2}\right)$ by spin coating a $7.5 \mathrm{mg} / \mathrm{ml} \mathrm{solution} \mathrm{of} \mathrm{p}(\mathrm{g} 2 \mathrm{~T}$ TT) in chloroform heated to $60^{\circ} \mathrm{C}$ onto native oxide $\mathrm{p}+$ silicon substrates at $600 \mathrm{rpm}$ for $15 \mathrm{~s}$, then $1000 \mathrm{rpm}$ for $60 \mathrm{~s}$. Spin coating was followed by brief drying (60s) on a hot plate at $60^{\circ} \mathrm{C}$ and longer drying (4h) in $\mathrm{N}_{2}$ to remove residual solvent. Prior to coating, the solution was left stirring overnight at $60^{\circ} \mathrm{C}$ and filtered using a glass fiber filter with $0.45 \mu \mathrm{m}$ of pore size. Samples were measured in various conditions with two different $\mathrm{NaCl}_{(\mathrm{aq} .)}$ concentrations: $1 \mathrm{M}$ and $10 \mathrm{mM}$. For the samples that were electrically gated, a $80 \mu \mathrm{l}$ droplet of electrolyte was placed on a $\mathrm{p}(\mathrm{g} 2 \mathrm{~T}-\mathrm{TT})$ film, where an $\mathrm{Ag} / \mathrm{AgCl}$ pellet electrode was immersed and a voltage was applied across the $\mathrm{Ag} / \mathrm{AgCl}$ and $\mathrm{p}+$ silicon substrate electrodes. After the doping procedure, films were rinsed in DI water and dried using a $\mathrm{N}_{2}$ gun. Grazing incidence wide angle X-ray scattering (GIWAXS) was performed at the Stanford Synchrotron Radiation Lightsource (SSRL) on beam line 11-3 using an area detector (Rayonix MAR-225) and incident energy of $12.73 \mathrm{keV}$. The distance between sample and detector was $320.8 \mathrm{~mm}$ and it was calibrated using $\mathrm{L} \mathrm{LaB}_{6}$ polycrystalline standard. The incidence angle $\left(0.1^{\circ}\right)$ was slightly larger than the critical angle, ensuring that we sampled the full depth of the film. All X-ray measurements were performed in Helium environment to minimize air scattering and beam damage to samples. Raw data were normalized by detector counts and thickness, and reduced and analyzed using a combination of Nika 1D SAXS ${ }^{29}$ and WAXStools software packages in Igor Pro. ${ }^{30}$

\section{Raman spectroscopy}

For the Raman spectroelectrochemical investigation, two identically prepared p(g2T-TT) films were spin coated on transparent glass/Ti-3nm/Au-18nm substrates fabricated using RF magneton sputtering. The substrates were transparent and conductive to allow both doping as well access to the Raman beam. The films were immersed either in $\mathrm{NaCl}_{(\mathrm{aq} .)} 0.01$ and $1 \mathrm{M}$ solutions, and an $\mathrm{Ag} / \mathrm{AgCl}$ electrode was used for the in-situ doping experiments. The resonant Raman spectra of the dry and wet samples were measured using a Witec alpha Raman spectrometer with the excitation beam line He-Ne laser of wavelength $632.8 \mathrm{~nm}, 50 \mu \mathrm{W}$ power to avoid photothermal effects. The dispersion gratings were $600 \mathrm{gr} / \mathrm{mm}$ and $1800 \mathrm{gr} / \mathrm{mm}$. The dry spectrum was collected with a $100 \mathrm{X}$ objective, while for the spectrum of the film in solution we used a $63 \mathrm{x}$ water compatible objective. Both objectives have a comparable spatial resolution about $600 \mathrm{~nm}$. For each condition, we mapped the sample with 4x4 points to average out the representative spectrum.

\section{Spectroelectrochemistry measurements}

Spectroelectrochemistry measurements were performed using a PGSTAT101 potentiostat in a three-electrode setup. The polymer was spin coated from a $5 \mathrm{mg} / \mathrm{mL}$ solution in chloroform on FTO-coated glass slides which acted as the working electrode. The films were placed in a holder with optical windows, integrated with a UV-1601 UV-VIS Shimadzu UV-Vis spectrometer. A Pt mesh was used as the counter electrode and an $\mathrm{Ag} / \mathrm{AgCl}$ electrode as the reference electrode ( $3 \mathrm{M} \mathrm{NaCl}$ solution). A background measurement was taken with a clean FTO substrate. The indicated voltages were applied versus $V_{\mathrm{OC}}$ (to compensate for any changes in the threshold voltage) for $10 \mathrm{~s}$ until the current stabilized prior to recording of the spectrum. To avoid faradaic side reactions on the FTO surface, epoxy glue was applied to passivate the electrolyte exposed areas which remained uncovered by the polymer film.

\section{Atomic Force Microscopy (AFM)}

AFM measurements were performed in tapping mode, using Agilent 5500 SPM-AFM equipment and Bruker AFM probes with spring constant $\mathrm{k}=2.8 \mathrm{mN} / \mathrm{cm}^{2}$. The measurements were performed with two different $\mathrm{p}(\mathrm{g} 2 \mathrm{~T}-\mathrm{TT})$ films which were spin coated on glass/Au substrates from a $5 \mathrm{mg} / \mathrm{ml}$ solution in chloroform. First, we took the AFM images of both films in ambient conditions (as-cast). The films were then immersed in the corresponding electrolyte, doped at $-0.5 \mathrm{~V}$ vs $\mathrm{Ag} / \mathrm{AgCl}$ for 5 minutes, de-doped at $0 \mathrm{~V}$ for 5 minutes and dried again before monitoring the surface in ambient conditions. 


\section{RESULTS AND DISCUSSION}

\section{The influence of water on the electrochemical doping of p(g2T-TT)}

The electrochemical reactions in a p-type organic semiconductor-aqueous electrolyte system involve the injection of charge carriers $\left(e^{-}\right)$and penetration of hydrated ions $\left(A^{-}\right)$to compensate these charges on the backbone of the semiconducting polymer $(P)$ :

$$
P^{0}+A^{-} \rightleftharpoons P^{+}: A^{-}+e^{-}
$$

This phenomenon can be studied by EQCM-D, a molecular balance that monitors in-situ changes in the mass of an electroactive film coated on a piezoelectric quartz crystal while it undergoes an electrochemical reaction. ${ }^{31}$ In general, a decrease in the oscillation frequency $(f)$ of the QCM-D crystal indicates an increase of its mass. For a soft film, the decrease in $f$ is accompanied with an increase in the dissipation of energy $(D)$ as a result of energy losses during oscillations. ${ }^{32}$ In order to determine the amount of water incorporated into $\mathrm{p}(\mathrm{g} 2 \mathrm{~T}-\mathrm{TT})$ during electrochemical doping, we studied the EQCM-D response of $\mathrm{p}(\mathrm{g} 2 \mathrm{~T}-\mathrm{TT})$ films immersed in aqueous electrolytes of four different $\mathrm{NaCl}$ concentrations, i.e., $\mathrm{NaCl}_{(\mathrm{aq} .)} 10 \mathrm{mM}, 100 \mathrm{mM}, 1 \mathrm{M}$ and $6 \mathrm{M}$. With an increase in the concentration of $\mathrm{NaCl}_{(\mathrm{aq} .)}$, the hydration shell around the anions as well as the number of ion-free water molecules within the electrolyte solution reduce significantly. ${ }^{33}$ By changing the electrolyte concentration, we, therefore, aim to modulate the amount of water injected into the film alongside the $\mathrm{Cl}^{-}$ions. First, we measure the swelling of the polymer prior to biasing, which is due to water and passive ion diffusion. We find that passive swelling is nearly identical in all concentrations, accounting to $10-13 \%$ of mass increase (Figure $\mathrm{S} 1$ and Table $\mathrm{S} 1)$. Once the QCM-D signals $(\Delta f$ and $\Delta D)$ are stabilized, i.e., $\mathrm{p}(\mathrm{g} 2 \mathrm{~T}-\mathrm{TT})$ films are in thermodynamic equilibrium with the electrolyte, sequential doping and de-doping potential pulses are applied and the corresponding changes in QCM$\mathrm{D}$ signals are recorded, as shown in Figure S2. For all the films, the changes in $\Delta f$ and $\Delta D$ upon doping (i.e. $V>$ open circuit voltage $\left.\left(V_{\mathrm{OC}}\right) \approx 0 \mathrm{~V}\right)$ indicate an increase in the mass of the film, which is due to uptake of $\mathrm{Cl}^{-}$ions and water molecules. When the potential returns to $V_{\mathrm{OC}}$, the signals reverse due to expulsion of water and $\mathrm{Cl}^{-}$ions from the films. A schematic representation of the ion drift in and out of the films during the EQCM-D measurements is shown in Figure S3. We convert the EQCM-D signals into mass changes using viscoelastic modelling and the results are shown in Figure 1a-b, (see experimental section for more information on the model used). When the polymer is doped with less concentrated $\mathrm{NaCl}_{(\mathrm{aq} .)}$, the film gains more mass for the same applied potential. For instance, at $0.5 \mathrm{~V}$, we calculate a mass increase of $5.6 \mu \mathrm{g} / \mathrm{cm}^{2}$ in $\mathrm{NaCl}_{\text {(aq.) }} 10 \mathrm{mM}$, while this value is only $2.75 \mu \mathrm{g} / \mathrm{cm}^{2}$ in $\mathrm{NaCl}_{\text {(aq.) }} 6$ M. This corresponds to an increase in mass of $86 \%$ and $42 \%$, in $10 \mathrm{mM}$ and $6 \mathrm{M} \mathrm{NaCl}_{(\mathrm{aq} .)}$ respectively, compared with the equilibrium conditions (in the electrolyte, before bias). In addition, when the potential is reverted to $0 \mathrm{~V}$, a fraction of the injected mass remains in the film, which is higher at lower $\mathrm{NaCl}$ concentrations (e.g., $2.61 \mu \mathrm{g} / \mathrm{cm}^{2}$ for $\mathrm{NaCl}_{\text {(aq.) }} 10 \mathrm{mM}$ and $0.49 \mu \mathrm{g} / \mathrm{cm}^{2}$ for $\mathrm{NaCl}_{\text {(aq.) }} 6 \mathrm{M}$ ).
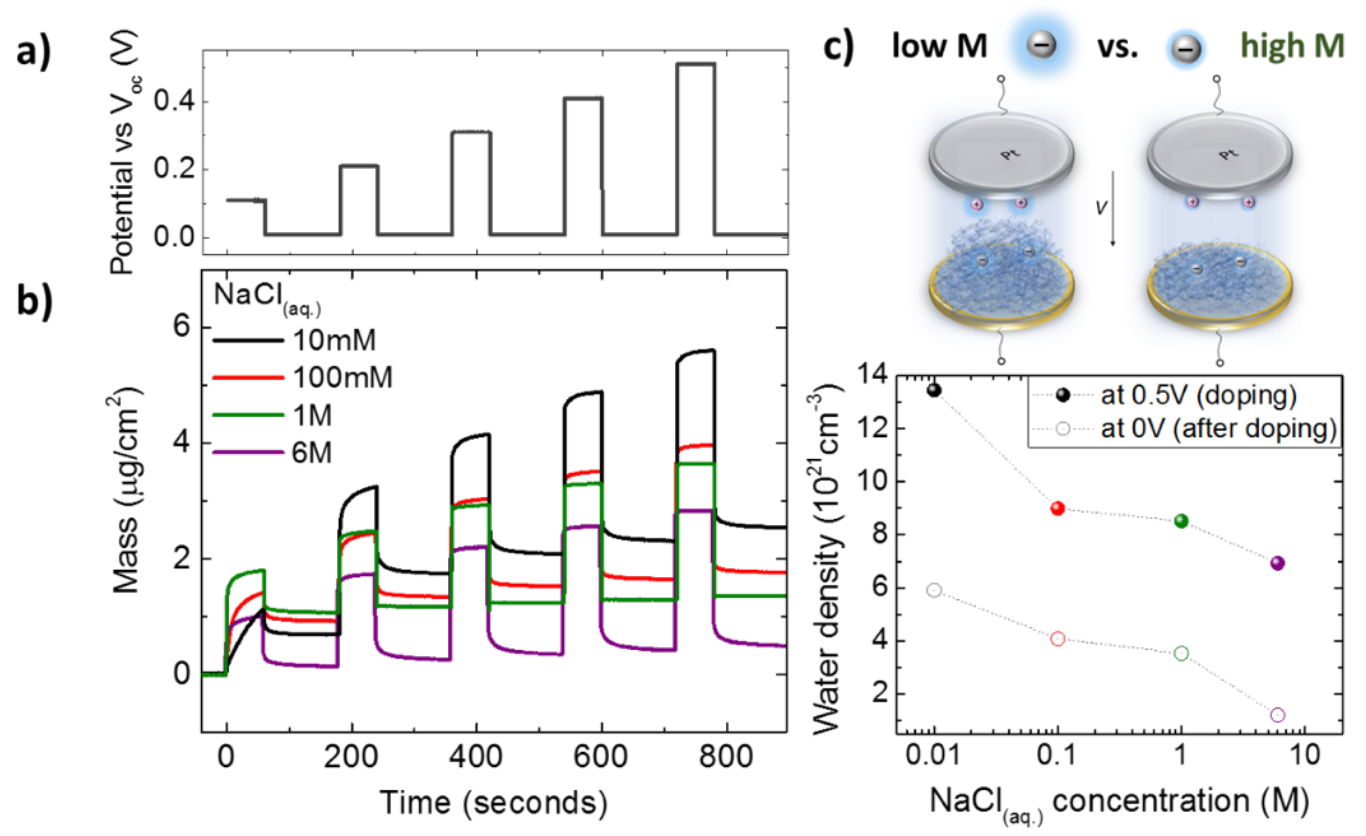

Figure 1: a) The applied potential waveform as a function of time. Square shaped doping pulses are applied for 60 seconds and range from $0.1 \mathrm{~V}$ to $0.5 \mathrm{~V} v s V_{\mathrm{OC}}$, with a de-doping potential applied at $0 \mathrm{~V}$ lasting for 120 seconds in between each doping pulse. b) Changes in the mass of the films when doped in four electrolytes of varying ion concentrations. c) Top: A schematic representation of $\mathrm{p}(\mathrm{g} 2 \mathrm{~T}-\mathrm{TT})-\mathrm{NaCl}(\mathrm{aq}$. system in the EQCM-D chamber during doping in low and high concentration electrolyte solutions. Bottom: The number of water molecules injected into the films at the end of the doping pulse at $0.5 \mathrm{~V}$ and remaining in the film upon the subsequent de-doping pulse applied at $0 \mathrm{~V}$ as a function of $\mathrm{NaCl}$ concentration.

Whereas the measured charge directly corresponds to the number of doping anions in the film, water uptake is also to be expected. In fact, the mass calculated from the injected anions is smaller than the measured mass (Figure S4). This discrepancy must thus correspond to the mass of water being dragged in the polymer. The water taken up by the films increases with a decrease in electrolyte 
concentration due to larger degree of hydration of anions therein (Figure 1c, $0.5 \mathrm{~V}$ ). Moreover, a fraction of water remains in the film even after a de-doping pulse is applied (Figure $1 \mathrm{c}, 0 \mathrm{~V}$ ), and this is most pronounced in dilute electrolytes. In addition, changes in the dissipation of energy upon doping with low concentration $\mathrm{NaCl}_{(\text {aq.) }}$ are larger compared to high concentration $\mathrm{NaCl}_{(\mathrm{aq} .)}(\mathrm{Figure} \mathrm{S} 3$ ), indicating that the film becomes softer due to increased water uptake. We note that in these solutions, osmosis also plays a role in determining the water drift. The osmosis effect is significantly large in the case of $\mathrm{NaCl}_{(\mathrm{aq} .)} 10 \mathrm{mM}$ due to the maximized difference in solute concentration between this electrolyte and the film. Bay et al. suggested that very large volume changes that polypyrrole films undergo during electrochemical reduction are due to the osmotic forces which cause water molecules to move into the polymer in quantities far in excess of those in the solvation shell of the ions in the electrolyte. ${ }^{34}$ Similar observations are reported by Maw and coworkers who showed that during electrochemical switching, water is carried in and out of the polymer films together with electrolyte ions, but also independently as a result of osmotic pressure. ${ }^{35}$ These results evidence two important phenomena regarding doping of an organic semiconductor in aqueous electrolytes: 1) the dopant anions that enter the film are hydrated and 2), the film swells more upon doping with low concentration electrolytes and retains most of these water molecules compared with operation at high concentration electrolytes.

The hydration of the polymer film affects also the dynamics of ion uptake. From the mass uptake $v s$ time curves in Figure $1 \mathrm{~b}$, we calculated the time required for each $\mathrm{p}(\mathrm{g} 2 \mathrm{~T}-\mathrm{TT})$ film to accumulate $90 \%$ of the total mass $(\tau)$ upon doping with these solutions (Figure 2a), which is a direct measurement of the speed of mass loading into the film, i.e. ionic charging. The ionic charging is slowest in $\mathrm{NaCl}_{(\mathrm{aq} .)} 10 \mathrm{mM}$, and becomes faster as the electrolyte concentrations increases regardless of the magnitude of the doping pulse. The fastest ionic charging is, however, achieved at $\mathrm{NaCl}_{(\text {aq. }} 1 \mathrm{M}$, rather than $\mathrm{NaCl}_{\text {(aq.) }} 6 \mathrm{M}$. In addition, assuming that the ion injection into $\mathrm{p}(\mathrm{g} 2 \mathrm{~T}-\mathrm{TT})$ is governed by semi-infinite linear diffusion, we use Cottrell equation to extract the diffusion coefficient of $\mathrm{Cl}^{-}$anions. We find that for all doping potentials, the diffusion coefficient of the dopant increases with a decrease in electrolyte concentration (Figure 2b). The ions in $\mathrm{NaCl}_{\text {(aq.) }} 6 \mathrm{M}$ exhibit however the slowest diffusion. These results suggest that the injection/drift of ions is strongly affected by the ion-counterion $\left(\mathrm{Cl}^{-}-\mathrm{Na}^{+}\right)$attractive forces which are most pronounced in the highest concentration electrolyte. These forces delay the ion injection from the electrolyte, opposing their drift into $\mathrm{p}(\mathrm{g} 2 \mathrm{~T}-\mathrm{TT})$. Thus, the fastest ionic charging is achieved when the polymer film is doped in $\mathrm{NaCl}_{(\mathrm{aq} .)} 1 \mathrm{M}$. At this concentration, the optimum hydration conditions are achieved, i.e., the polymer swelling is moderate while the $\mathrm{Cl}^{-}-\mathrm{Na}^{+}$attractive forces do not significantly hinder the drift of anions. 

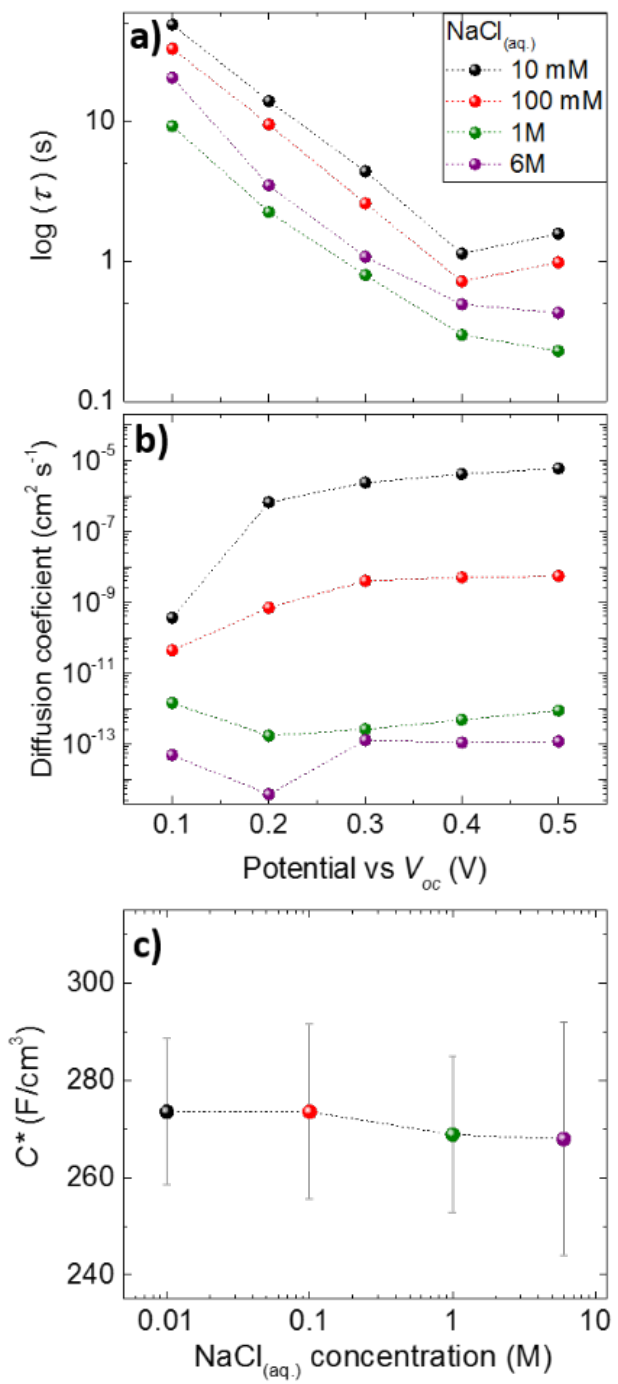

Figure 2. a) The mass loading time $(\tau)$ calculated at each doping pulse in electrolytes of different ion concentrations. The data are based on the mass $v s$ time plots of Figure $1 \mathrm{~b}$. b) Diffusion coefficient of $\mathrm{Cl}^{-}$anions in different electrolytes as a function of doping bias. The values are calculated from the chronoamperometry data (Figure S4) using Cottrell equation. c) Volumetric capacitance of the films as a function of $\mathrm{NaCl}_{(\text {aq. }}$ concentration measured at $0.5 \mathrm{~V} v s V_{\mathrm{OC}}$. Error bars correspond to standard deviation from the measured average of four films with the electrolytes in question.

To further reveal the influence of water on the speed of ionic charging, we used electrochemical impedance spectroscopy (EIS) which allows us to investigate ionic charging at different time scales. We performed EIS prior to biasing as well as at a doping potential ( $V$ $=+0.5 \mathrm{~V} v s V_{\mathrm{OC}}$ ) for all the films at different $\mathrm{NaCl}$ concentrations (Figure S5a-d). Based on these impedance data, we extracted capacitance $v s$ frequency plots, all exhibiting a cut-off frequency after which the capacitance drops (Figure S5e-f, Figure 2c). In $\mathrm{NaCl}_{\text {(aq.) }} 1 \mathrm{M}$, the capacitance curve reaches a plateau at $8.5 \mathrm{~Hz}$, i.e., a frequency higher than all the other $\mathrm{NaCl}$ concentrations studied (Figure S5f). The ionic charging of the film is thus fastest in $\mathrm{NaCl}_{(\mathrm{aq} .)} 1 \mathrm{M}$, in accordance with Figure 2a. Moreover, prior to doping, the capacitance values at low frequencies (i.e. $0.1 \mathrm{~Hz}$ ) are similar for all the systems $\left(\mathrm{ca} .2^{*} 10^{-4} \mathrm{~F}\right.$ at $\left.0.1 \mathrm{~Hz}, \mathrm{Figure} \mathrm{S} 5 \mathrm{e}\right)$, which is also the case when the samples are doped (ca. $1.8^{*} 10^{-3} \mathrm{~F}$ at $0.1 \mathrm{~Hz}$, Figure S5f). Based on the low-frequency capacitance of the doped polymers, the volumetric capacitance is calculated to be $285 \mu \mathrm{F} / \mathrm{cm}^{3}$ which is on par with the previously reported values (Figure $2 \mathrm{c}$ ). ${ }^{13}$ The same $C^{*}$ calculated for all the systems under investigation means that at steady-state conditions, the number of ions injected during doping is the same regardless of the electrolyte concentration. Based on our electrochemical analysis, it is clear that more water is dragged in the $\mathrm{p}(\mathrm{g} 2 \mathrm{~T}-\mathrm{TT})$ film when doped in less concentrated $\mathrm{NaCl}$ solution. The excess water molecules lead to large volumetric expansion of the film and slow down the ionic charging, however, the charging capacity of the film is not affected by its hydration state.

\section{The influence of water on the structural properties of $\mathrm{p}(\mathrm{g} 2 \mathrm{~T}-\mathrm{TT})$}

To understand how the injected ions and water influence the structural properties of the film, we collected ex-situ grazing incidence wide angle scattering (GIWAXS) patterns of thin films electrochemically doped in $\mathrm{NaCl}_{(\text {aq.) }} 1 \mathrm{M}$ and $10 \mathrm{mM}$. In its dry, as-cast condition, p(g2T-TT) presents a predominantly edge-on texture, ${ }^{13}$ with lamellar and $\pi$-stacking distances of 13.45 and $3.79 \AA$, 
respectively. As it can be seen in Figure 3, exposure of the polymer to $\mathrm{NaCl}_{(\text {aq. }} 1 \mathrm{M}$ and $\left.\mathrm{NaCl}_{(\text {aq. }}\right) 10 \mathrm{mM}$ at $V_{\text {applied }}=0 \mathrm{~V}$ does not largely affect the lattice spacing of the ordered regions (Step 2). Upon electrochemical doping $\left(V_{\text {applied }}=-0.5 \mathrm{~V}\right.$, Step 3 ), however, the crystallites experience a permanent expansion in the lamellar spacing $(\sim 14-15 \%)$ and contraction in the $\pi-\pi$ stacking direction $(\sim 7$ $-8 \%$ ). A change in orientation in reciprocal space of the $\pi-\pi$ stacking peak position, visible in the GIWAXS patterns (Figure S6), suggests that the crystallites in the polymer experience a unit cell distortion upon doping. Similar to the irreversible effects of water uptake on the bulk properties of the film as measured by EQCM-D, de-doping the films $\left(V_{\text {applied }}=0 \mathrm{~V}\right.$, Step 4$)$ does not the reverse the lattice distortion to the initial, dry, crystal structure. As our EQCM-D and EIS results show, upon doping anions and water penetrate into the bulk of the polymer. The rather drastic lamellar expansion upon doping confirms that anions can also infiltrate into the crystallites, likely accumulating between the glycol side chains to compensate for electronic charges in the polymer backbone. This is in agreement with previous literature evidencing that electrochemical doping in non-aqueous electrolytes with anions larger in size than $\mathrm{Cl}^{-}$, such as $\mathrm{BF}_{4}^{-}, \mathrm{AsF}_{6}^{-},{ }^{36}$ or bistriflimide (TFSI- ${ }^{20}$ produces a lamellar expansion in poly(3-alkylthiophenes) (i.e., $\left.\mathrm{P} 3 \mathrm{HT}^{2}\right)$ attributed to anions being located between the alkyl chains. In $\mathrm{p}(\mathrm{g} 2 \mathrm{~T}-\mathrm{TT})$, however, due to the hydrophilic nature of the side chains and large water uptake upon doping (Figure 1c), we also expect water to accumulate between the side chains of the crystallites.

The influence of water on the crystallites of the polymer is subtle. Although water uptake in the bulk of the polymer almost doubles when left at doped state after $-0.5 \mathrm{~V}$ with $10 \mathrm{mM} v s 1 \mathrm{M} \mathrm{NaCl}$, differences in the lattice spacings of the crystallites with salt concentration are rather small. In comparison to films doped with $\mathrm{NaCl}_{(\text {(aq.) }} 1 \mathrm{M}$, the lamellar spacing of films doped with $\mathrm{NaCl}_{(\text {(aq.) }} 10$ $\mathrm{mM}$ presents an additional expansion of $0.15 \AA$ (see Table S2), which is well above the experimental error $(\sim 0.01 \AA$ ). In this doping condition, differences in $\pi-\pi$ spacing are within the experimental error and, thus, no comparisons can be performed in this crystallite direction. De-doping of the polymer with different electrolyte concentrations (Step 4) produces no discernable differences in the lattice spacings. Given the small changes in lamellar spacing relative to the molecular size of water $(1.76 \AA)^{37}$ and $\mathrm{Cl}^{-}(\mathrm{crystal}$ radius: $3.62 \AA)^{37}$ we suggest that the small increase in lamellar expansion when the polymer is doped with low concentration electrolytes is due to a slight increase in water uptake by the crystallites. In addition, the permanent changes in the crystallites induced after doping also suggest that water could be residing in the crystallites, even when the polymer is reduced. Complete out-of-plane and in-plane lineouts and 2D GIWAXS patterns are included in Figure S6 and S7.

a)

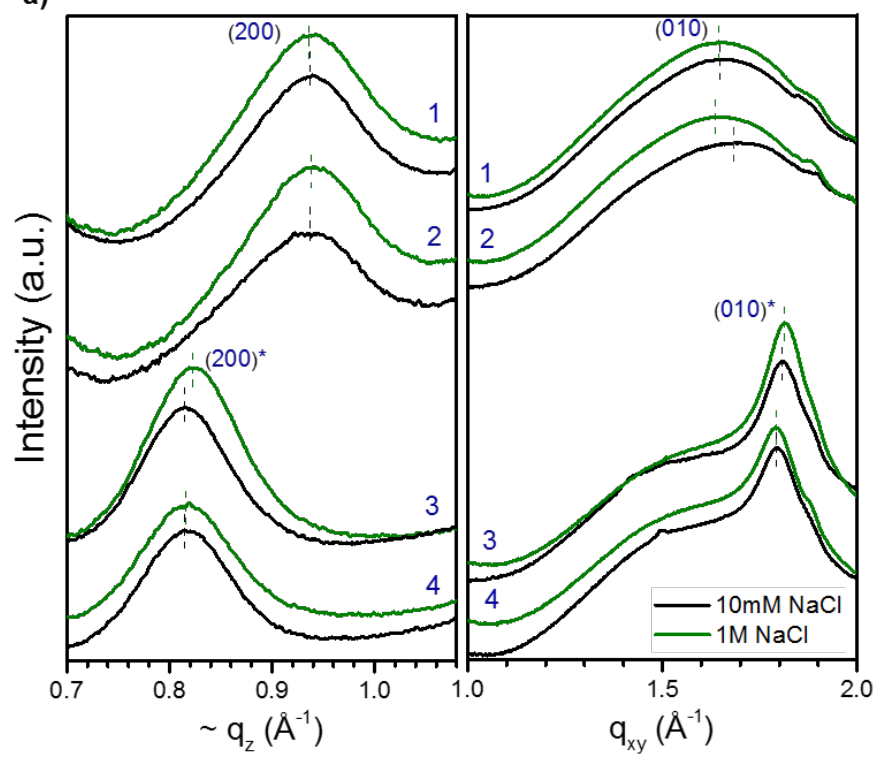

b)

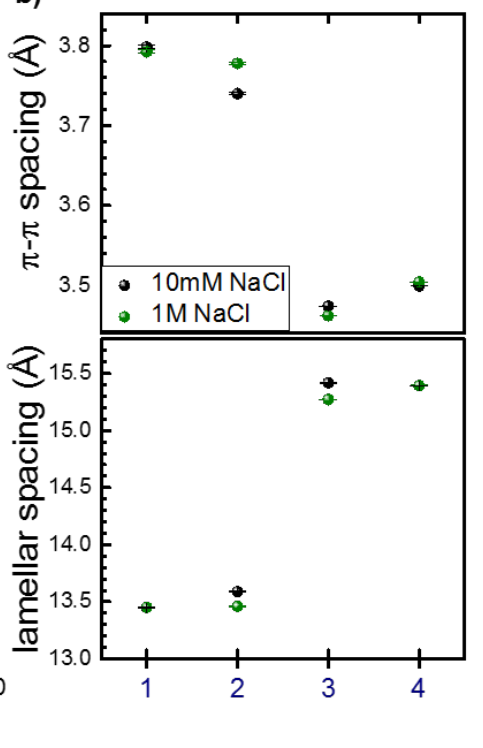

Figure 3. a) Out-of-plane $\left(\mathrm{q}_{\mathrm{z}}\right)$ and in-plane $\left(\mathrm{q}_{\mathrm{xy}}\right) \mathrm{X}$-Ray scattering lineouts for the $(200)$ and $(010)$ peaks, respectively, of $\mathrm{p}(\mathrm{g} 2 \mathrm{~T}-\mathrm{TT})$ films doped with $\mathrm{NaCl}_{\text {(aq.) }} 10 \mathrm{mM}$ (black lines) and $\mathrm{NaCl}_{\text {(aq.) }} 1 \mathrm{M}$ (green lines). Numbers in parenthesis correspond to different conditions of the polymer: (1) dry, as-cast, (2) immersed in electrolyte, (3) doped at $0.5 \mathrm{~V} v s V_{\mathrm{OC}}$ and (4) subsequently de-doped at $V_{\mathrm{OC}}$. Asterisks denote position of scattering peaks after lattice distortion induced by electrochemical doping. Dashed lines correspond to center of scattering peaks. b) Lattice spacing values of the $\pi$ - $\pi$ stacking and lamellar distances extracted from fitting peak diffraction positions of the (010) and (200) peaks, respectively. Error bars in lattice spacing correspond to propagated error from peak fitting.

GIWAXS data suggest that the majority of water uptake occurs in the amorphous regions of the polymer. We thus performed in-situ Raman spectroscopy to probe the impact of doping on the bulk of the polymer as the technique monitors the film structure regardless of its crystal or amorphous content and is sensitive to conformational changes and stacking of conjugated components. ${ }^{38}$ The molecular structure of neutral p(g2T-TT) is shown in Figure 4a, depicting a distribution of charge mainly localized around the backbone within the aromatic thiophene-thienothiophene rings. The presence and the degree of delocalization of $\pi$-electrons enhance and modulate both the electronic absorption in the visible range, ${ }^{13}$ and the polarizability, resulting in a strong Raman scattering signal, very sensitive to changes in backbone vibrations. Figure $4 \mathrm{~b}$ shows the high energy Raman spectrum of a dry $\mathrm{p}(\mathrm{g} 2 \mathrm{~T}-\mathrm{TT})$ film that consists of two distinct regions ascribed to the backbone and the side chains. The main peaks in the spectral region between 1200$1600 \mathrm{~cm}^{-1}$ are associated with the vibrations of the backbone (which benefits from an enhanced polarizability due to the $\pi$-delocalized electrons compared to the side chains) and, in particular, the three main visible bands (A, B, C in Figure 4b) refer to the in-plane ring 
modes: $\mathrm{C}=\mathrm{C}$ stretching $\left(\simeq 1406 \mathrm{~cm}^{-1}\right.$, thienothiophene core $), \mathrm{C}=\mathrm{C}$ symmetric stretching $\left(\simeq 1448 \mathrm{~cm}^{-1}\right.$, thiophene core $)$, and $\mathrm{C}=\mathrm{C} / \mathrm{C}$ $\mathrm{C}$ asymmetric stretching/shrinking collective vibrational mode $\left(\simeq 1494 \mathrm{~cm}^{-1}\right)$. The latter (peak C) is associated with oscillations of the nuclei along the path of the molecular axis from the ground to the excited state, sensitive to $\pi$-electron delocalization, electronphonon coupling or polaron formation, and as such it is regarded as an indicator of structural-electronic changes. ${ }^{39}$ The region below ca. $1300 \mathrm{~cm}^{-1}$, on the other hand, contains $\mathrm{C}-\mathrm{C}$ skeletal stretching and $\mathrm{C}-\mathrm{H}$ bending. The $\mathrm{C}-\mathrm{O}$ vibration, indicative of the ethylene glycol side chains, is characterized with a less pronounced non-resonant Raman line at ca. $1100 \mathrm{~cm}^{-1} .{ }^{40}$

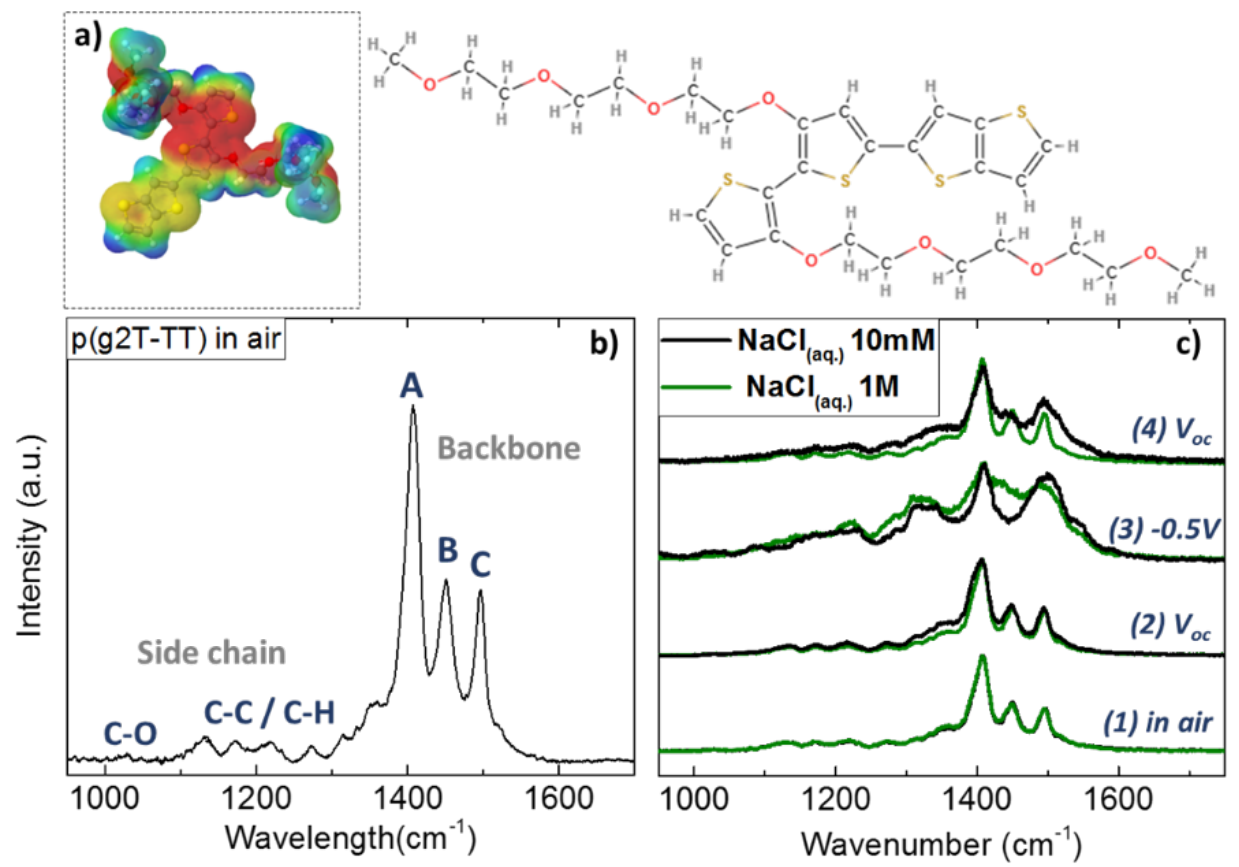

Figure 4. a) The molecular structure of $\mathrm{p}(\mathrm{g} 2 \mathrm{~T}-\mathrm{TT})$ showing the distribution of charge, with increasing electron density from blue to red. b) Characteristic Raman spectrum of $\mathrm{p}(\mathrm{g} 2 \mathrm{~T}-\mathrm{TT})$ film recorded in air. The peaks labeled with $\mathrm{A}, \mathrm{B}$ and $\mathrm{C}$ are attributed to $\mathrm{C}=\mathrm{C}$ stretching, thienothiophene core $\left(\simeq 1406 \mathrm{~cm}^{-1}\right), \mathrm{C}=\mathrm{C}$ symmetric stretching $\left(\simeq 1448 \mathrm{~cm}^{-1}\right)$ and $\mathrm{C}=\mathrm{C} / \mathrm{C}-\mathrm{C}$ asymmetric stretching/shrinking $(\simeq 1494 \mathrm{~cm}-1)$, respectively. The region between ca. $1000-1300 \mathrm{~cm}^{-1}$ are mainly due to the side chains. c) Changes in the Raman spectra of identically prepared films during doping in $\mathrm{NaCl}_{(\text {aq.) }} 10 \mathrm{mM}$ (black lines) and $\mathrm{NaCl}_{(\mathrm{aq} .)} 1 \mathrm{M}$ (green lines). The spectra were recorded when the film was dry, i.e., in air (1), immersed in electrolyte (2), doped at $-0.5 \mathrm{~V} v s V_{\mathrm{OC}}(3)$ and subsequently de-doped at $V_{\mathrm{OC}}(4)$.

As shown in Figure 4c, exposing the film to the corresponding electrolyte does not affect the thiophene ring spectral region (compare Step 1 with Step 2). On the contrary, the Raman spectra of both films under investigation undergo significant changes as they are doped (Step 3). Particularly, in $\mathrm{NaCl}_{\text {(aq.) }} 1 \mathrm{M}$ (green lines), peak B becomes broader, blue-shifts and nearly merges with peak A. In $\mathrm{NaCl}_{(\text {aq. }} 10 \mathrm{mM}$, peak B disappears while peak $\mathrm{C}$ increases in relative intensity and breadth (black lines). In both electrolytes, we observe a significant decrease in the overall Raman spectral intensity, in particular for peaks B and C (Figure S8). Another region that is affected by doping is the interring C-C stretching vibration at ca. 1215 and $1270 \mathrm{~cm}^{-1}$ indicating an overall reduced bond order in the polymer backbone. This is a typical consequence of charge redistribution that gives rise to a quinoid-type configuration, reducing the $\pi$-electron delocalization and the degree of long-structural order in poly(thiophenes). ${ }^{41}$ The changes in the backbone region upon doping are attributed to the presence of $\mathrm{Cl}^{-}$ions close to the thienothiophene rings and the formation of polarons, causing significant distortions on the vibrational properties of the ring bonds. These distortions are more pronounced in $\mathrm{NaCl}_{(\mathrm{aq} .)} 1 \mathrm{M}$ compared to $\mathrm{NaCl}_{\text {(aq.) }} 10 \mathrm{mM}$. We postulate that the limited hydration of the film in concentrated electrolytes allows a closer interaction of ions with the backbone.

Finally, when the potential is reversed to $V_{\mathrm{OC}}$, while the doping induced changes along the backbone are partially recovered for the film in $\mathrm{NaCl}_{(\mathrm{aq} .)} 10 \mathrm{mM}$, these are more reversible in $\mathrm{NaCl}_{(\mathrm{aq} .)} 1 \mathrm{M}$ (Figure 4c, Step 4). This result is in accordance with our QCM-D findings, the fact that a substantial amount of mass remains in the film upon doping in dilute electrolytes. Moreover, looking closer at the spectral region associated with the side chains (ca. $1000-1300 \mathrm{~cm}^{-1}$ ), we see that upon de-doping, the formerly distinct, well separated peaks re-appear only in $\mathrm{NaCl}_{\text {(aq.) }} 1 \mathrm{M}$, but not in $10 \mathrm{mM}$ (Figure S9). Based on these findings, we suggest a route for water that is infiltrating into the film: water interacts mainly with the side chains, localizes in chain interstitial spaces and swelling of these regions disrupts the aggregates. In dilute electrolytes, as the doping induced hydration is high, water irreversibly leads to structural distortions.

The effect of electrochemical doping on the electronic properties of the film can be further investigated via spectroelectrochemistry measurements where we monitor the changes in the absorbance spectra of the polymer films during the application of a doping potential in each electrolyte. Figure S10a shows that in all electrolytes, the $\pi-\pi^{*}$ related absorption peak is bleached, while the absorption of the polaronic species increases with the increase in doping voltage. Notably, these changes are more prominent in concentrated electrolytes (Figure S10b-c), indicating a higher degree of anion-backbone coupling, in agreement with our in-situ 
Raman spectroscopy results. To monitor the effects of electrochemical doping on film morphology, we next performed atomic force microscopy (AFM) measurements. Figure S11 shows the AFM images of two polymer films in air before and after doping in the electrolyte in question. The film morphology changes significantly once the films were electrochemically addressed in either high or low concentration electrolyte. The permanent changes that we observe on the film surface agree well with the irreversible structural distortions suggested by Raman and GIWAXS data.

\section{The influence of water on the operation of OECTs}

In order to understand the influence of water coupled to the polymer film on OECT characteristics, we characterized micron-scale OECTs comprised of identically prepared p(g2T-TT) channels gated in the same four electrolytes. As shown in Figure 5a-b, upon application of a negative bias at the gate, the source-drain current increases, indicative of the accumulation mode of operation, regardless of the electrolyte concentration and the water coupled to the channel. However, the $\mathrm{ON}$ current is always higher at higher $\mathrm{NaCl}$ concentrations, as well as the transconductance (Figure 5a and 5b). We also observe a decent increase in the threshold voltage with an increase in electrolyte concentration (Figure S12). We hypothesize that since the ions are less hydrated in concentrated electrolytes, the ion-counterion forces start hindering their drift into the film, increasing the potential required to inject them..$^{24}$ Using bandwidth measurements (Figure S13a), ${ }^{28}$ we find that the hole mobility scales with the $\mathrm{NaCl}$ concentration: $\mu_{\mathrm{OECT}}$ is $0.15,0.20,0.22$ and $0.33 \mathrm{~cm}^{2} \mathrm{~V}^{-1} \mathrm{~s}^{-1}$ when doped in $\left.\mathrm{NaCl}_{(\mathrm{aq} .)}\right) 10 \mathrm{mM}, 100 \mathrm{mM}, 1 \mathrm{M}$ and $6 \mathrm{M}$, respectively (Figure $5 \mathrm{c}$ ). The extent of channel swelling influences also the transient characteristics of the OECTs. To determine the switching speed of the transistors, we monitored the change in drain current upon application of square voltage pulses at the gate electrode (Figure S13b). The current-time profiles follow an exponential behavior and the response times $\left(\tau_{O E C T}\right)$ of the devices are shown in Figure $5 \mathrm{~d}$. The devices switch ON fastest when they are gated in $\mathrm{NaCl}_{\text {(aq.) }} 1 \mathrm{M}$, while the slowest response is predominantly in $\mathrm{NaCl}_{\text {(aq.) }} 10 \mathrm{mM}$. At the highest $\mathrm{NaCl}_{\text {(aq.) }}$ concentration $(6 \mathrm{M})$, the low hydration of ions leads to attractive forces between $\mathrm{Cl}^{-}$and $\mathrm{Na}^{+}$counter ions, which oppose to the injection of $\mathrm{Cl}^{-}$ions into the film to compensate the polaron sites. Therefore, the OECTs gated in $\mathrm{NaCl}_{\text {(aq.) }} 6 \mathrm{M}$ switch ON slower compared with $1 \mathrm{M}$. Similar observations were reported by Lin et al. who show that at high electrolyte concentrations, a higher $V_{\mathrm{G}}$ is required to compensate the potential change at the interface between the electrolyte and a PEDOT:PSS film. ${ }^{42}$

Together with the temporal response of the drain current, we also measure the current flowing between the gate electrode and the channel (Figure S13c). The gate current is modulated by the ion movement in the electrolyte, which is then transduced as the drain current. The gate current is purely capacitive (notice the brief spikes at the beginning and end of the doping pulse) and should vanish at steady-state. The charge redistribution therein is thus correlated with the ionic charge injected from the electrolyte into the channel, as the same number of counter charge (cations) are injected to the gate electrode. The gate electrode accumulates the highest amount of charges at $\mathrm{NaCl}_{\text {(aq.) }} 1 \mathrm{M}$ (Figure S13d), as the ionic charging of the channel is the fastest in this electrolyte.
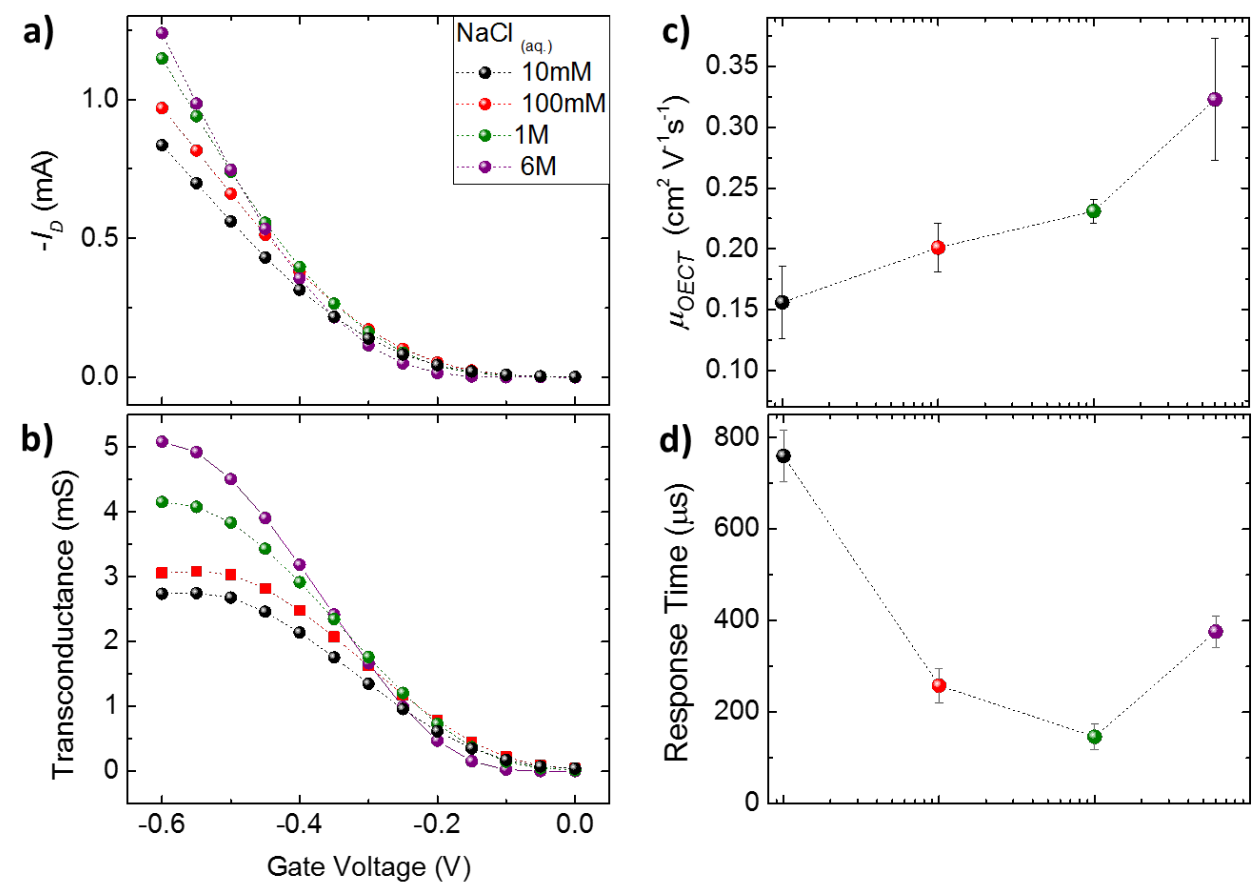

Figure 5. Gate voltage dependence of the a) drain current $\left(I_{\mathrm{D}}\right)$ and $(\mathbf{b})$ transconductance of OECTs comprising p $(\mathrm{g} 2 \mathrm{~T}-\mathrm{TT})$ in the channel $(W$ $=100 \mu \mathrm{m}, L=10 \mu \mathrm{m}, d=120 \mathrm{~nm})$. The devices are measured in $\mathrm{NaCl}_{(\mathrm{aq} .)}$ solutions of varying ion concentrations at $V_{\mathrm{D}}=-0.5 \mathrm{~V}$. c) Hole mobility $\left(\mu_{\mathrm{OECT}}\right)$ of $\mathrm{p}(\mathrm{g} 2 \mathrm{~T}-\mathrm{TT})$ film as a function of $\mathrm{NaCl}_{(\mathrm{aq} .)}$ concentration, calculated from the bandwidth measurements performed at $V_{\mathrm{G}}=$ $V_{\mathrm{D}}=-0.5 \mathrm{~V}$ as shown in Figure S13a. The error bars are derived from 4 different OECT channels measured at each concentration. d) Response time of the OECTs $\left(\tau_{\mathrm{OECT}}\right)$ as a function of $\mathrm{NaCl}$ concentration measured at $V_{\mathrm{G}}=V_{\mathrm{D}}=-0.5 \mathrm{~V}$. 
During the OECT operation, the channel hydrates significantly due to the dopant ions entering the film with their hydration shell. When the device is operated in low concentration $\mathrm{NaCl}_{(\mathrm{aq} .)}$, where $\mathrm{Cl}^{-}$ions drag more water with them during their drift, the channel swells more compared with when doping in high concentration electrolytes. As the film swells, it becomes softer (see the large changes in dissipation in Figure S2b). The more water the film gains upon doping, the less it is able to lose it upon de-doping. The osmosis effect also contributes to the extensive swelling observed in low concentration electrolytes: the doping potential pushes anions into a small volume of the polymer film, therefore, a large difference in ion concentration occurs between the electrolyte and the film. This enables free water molecules spontaneously moving into the film, most pronounced in dilute electrolytes. Figure 6 depicts the different swelling behavior of the channel when gated in low and high concentration electrolytes.

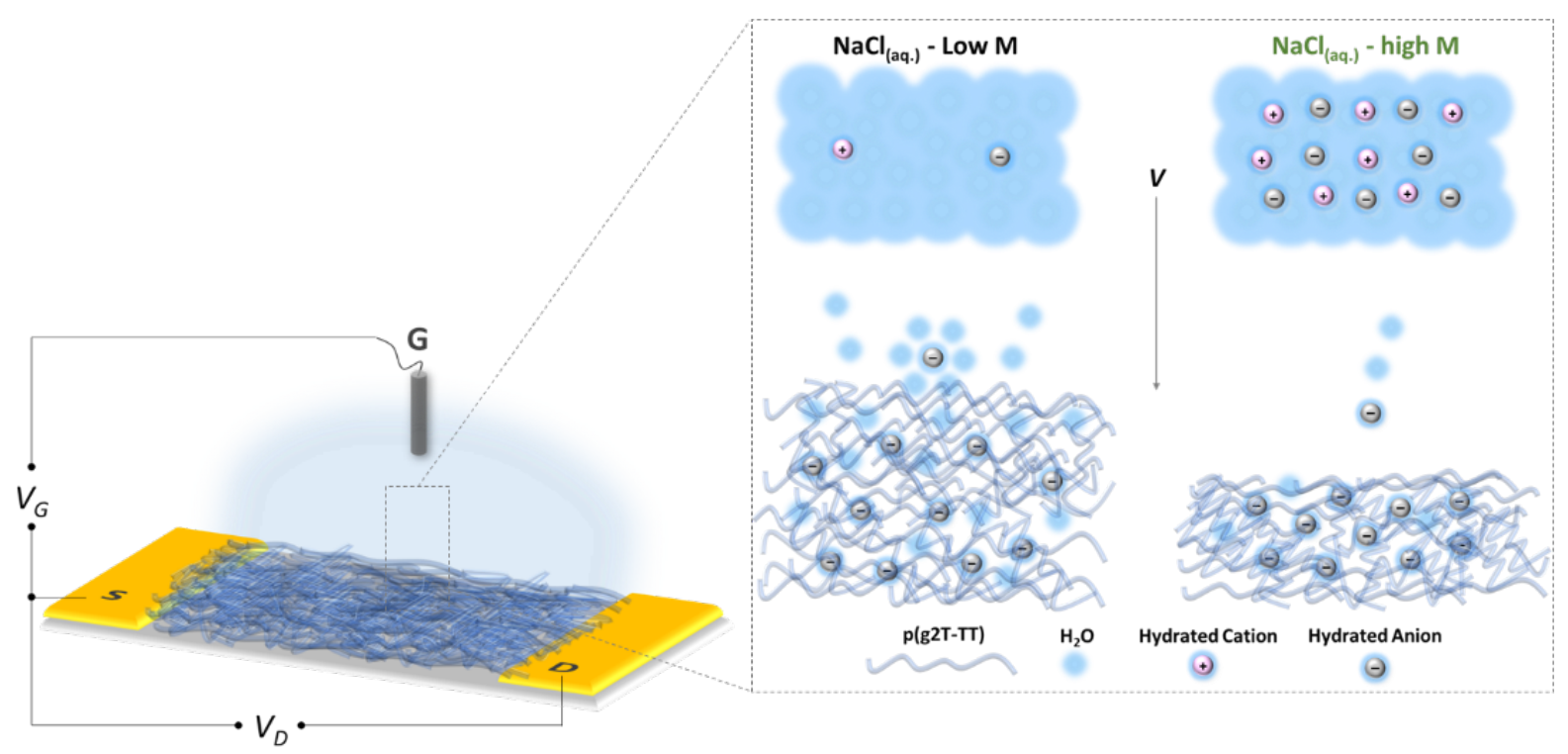

Figure 6: Schematic representation of an OECT channel comprised of $\mathrm{p}(\mathrm{g} 2 \mathrm{~T}-\mathrm{TT})$ and gated with an $\mathrm{Ag} / \mathrm{AgCl}$ electrode immersed in $\mathrm{NaCl}_{(\text {aq.) }}$ solutions with different ion concentrations. The magnified region depicts the polymer-electrolyte interface and the differences in the swelling behavior of the film at low and in high concentration electrolyte.

The water drifting into the film affects the polymer structure as well as the hole transport therein. Water causes a large volumetric expansion of the polymer film, but the swelling is not uniform throughout the bulk. Ex-situ GIWAXS measurements suggest that water molecules reside mostly in the disordered regions of the polymer, while anions accumulate amongst the side chains (in the interlamellar region of the crystallites) to compensate for electronic charges, possibly bringing along some water into the crystallites. In-situ Raman measurements reveal that side chains remain distorted upon a doping/de-dedoping cycle in low concentration $\mathrm{NaCl}_{(\text {aq.) }}$. The large water cloud around the side chains and in amorphous regions would result in an overall heterogeneous swelling of the polymer film upon doping: while these parts of the film swell with water, the crystalline regions show only a small extension in lamella spacing. Such a morphology may not be ideal for charge transport, loosening the connectivity of the crystallites that are responsible for charge transport. In fact, we find that hole mobility decreases as the channel swells further. Moreover, we postulate that the anions shed the outer water molecules around the side chains and as such their doping ability becomes independent of the electrolyte concentration. Accordingly, we measure similar capacitance values at low frequencies in all electrolytes, while hole transport is affected by the electrolyte concentration.

These structural changes have consequences on device performance. The transconductance $\left(g_{m}\right)$ of the OECTs scales with the product of the volumetric capacitance $\left(C^{*}\right)$ and the hole mobility $(\mu)$ according to $g_{m}=\frac{W}{L} d \mu C^{*}\left(V_{T}-V_{G}\right)$. As the capacitance is not affected by the channel hydration, it is the higher hole mobility that is responsible for the higher transconductance when the channel hydration is limited. The ON/OFF ratio of the OECTs is also higher when gated with high concentration electrolytes. The effect of water uptake is not limited to the steady-state characteristics of the OECTs. At low concentration electrolytes, the number of ions per unit volume is low, leading to a high electrolyte resistance (Figure S5, note the electrolyte resistance at high frequency). Considering that ionic transit time is $\tau=R C,{ }^{27}$ where $R$ is the electrolyte resistance and $C$ is the capacitance of the film, the increase in electrolyte resistance slows down the OECTs. In addition to that, for a rapidly switching channel, the ions need to move fast within the film to reach the polaron sites and at the same time the electronic carriers need to travel along the channel. At low concentration electrolytes, ionic charging of the film is delayed accompanied with a reduction in hole mobility, another reason why hydration of the channel leads to slow switching speeds in OECTs.

\section{Conclusions}

In summary, we showed, for the first time, the influence of water on the doping, structure and transport properties of a new class of amphiphilic organic semiconductors. Rather than using different anions with varying hydration behavior, or changing the polymer 
hydrophilicity, we simply change the electrolyte concentration to modulate the hydration properties of the dopant. This gives us a handle to solely observe the water drift in and out of the films and its consequences in device performance. The polymer film requires an optimum degree of hydration for efficient electrochemical doping in aqueous electrolytes as well as for fast and high gain accumulation mode OECTs. However, controlling the swelling of the channel can maximize the ON currents alongside an improvement of switching speeds since water accumulating in the film leads to structural changes that impair the hole mobility. Importantly, these results evidence major differences of these polymers compared to PEDOT based systems which are used in depletion mode devices where hydration is always beneficial for device operation. We suggest that minimizing the volumetric expansion of the polymer films during doping could be a key parameter to design fast and highly efficient ion-to-electron transduction devices. This work presents a solid understanding of the impact of hydration of mixed conductors on the operation of accumulation mode OECTs and lays the foundation for future design of efficient ion-to-electron transducers.

\section{ASSOCIATED CONTENT}

\section{Supporting Information}

Swelling and EQCM-D measurements and analysis, EIS, GIWAXS, Raman spectroscopy, Spectroelectrochemistry, AFM and transient OECT measurements. This material is available free of charge via the Internet at http://pubs.acs.org.

\section{AUTHOR INFORMATION}

\section{Corresponding Author}

*sahika.inal@kaust.edu.sa

\section{Author Contributions}

The manuscript was written through contributions of all authors. All authors have given approval to the final version of the manuscript.

\section{ACKNOWLEDGMENT}

The authors would like to thank Dr. George Nikiforidis for fruitful discussions. J.R. acknowledges support from the National Science Foundation (Grant No. NSF DMR-1751308 ). Portions of this research were carried out at the Stanford Synchrotron Radiation Lightsource, a national user facility operated by Stanford University on behalf of the U.S. Department of Energy, Office of Basic Energy Sciences.

\section{REFERENCES}

1. Inal, S.; Malliaras, G. G.; Rivnay, J., Benchmarking organic mixed conductors for transistors. Nat. Commun. 2017,8 (1), 1767. 2. Uzman, A., Molecular biology of the cell (4th ed.): Alberts, B., Johnson, A., Lewis, J., Raff, M., Roberts, K., and Walter, P. Biochem. Mol. Biol. Educ. 2003, 31 (4), 212-214.

3. Martin, D. C.; Malliaras, G. G., Interfacing Electronic and Ionic Charge Transport in Bioelectronics. ChemElectroChem 2016, 3 (5), 686-688

4. $\quad$ Lee, W.; Kim, D.; Matsuhisa, N.; Nagase, M.; Sekino, M.; Malliaras, G. G.; Yokota, T.; Someya, T., Transparent, conformable, active multielectrode array using organic electrochemical transistors. Proc. Natl. Acad. Sci. U. S. A. 2017, 114 (40), $10554-10559$.

5. $\quad$ Curto, V. F.; Marchiori, B.; Hama, A.; Pappa, A.-M.; Ferro, M. P.; Braendlein, M.; Rivnay, J.; Fiocchi, M.; Malliaras, G. G.; Ramuz, M.; Owens, R. M., Organic transistor platform with integrated microfluidics for in-line multi-parametric in vitro cell monitoring. Microsys. Nanoeng. 2017, 3, 17028.

6. $\quad$ Pappa, A.-M.; Parlak, O.; Scheiblin, G.; Mailley, P.; Salleo, A.; Owens, R. M., Organic Electronics for Point-of-Care Metabolite Monitoring. Trends Biotechnol. 2018, 36 (1), 45-59.

7. $\quad$ Pappa, A. M.; Ohayon, D.; Giovannitti, A.; Maria, I. P.; Savva, A.; Uguz, I.; Rivnay, J.; McCulloch, I.; Owens, R. M.; Inal, S., Direct metabolite detection with an n-type accumulation mode organic electrochemical transistor. Sci. Adv. 2018, 4 (6), eaat0911.

8. $\quad$ Rivnay, J.; Inal, S.; Salleo, A.; Owens, R. M.; Berggren, M.; Malliaras, G. G., Organic electrochemical transistors. Nat. Rev. Mater. 2018, 3, 17086.

9. $\quad$ Khodagholy, D.; Rivnay, J.; Sessolo, M.; Gurfinkel, M.; Leleux, P.; Jimison, L. H.; Stavrinidou, E.; Herve, T.; Sanaur, S.; Owens, R. M.; Malliaras, G. G., High transconductance organic electrochemical transistors. Nat. Commun. 2013, 4, 2133.

10. Inal, S.; Rivnay, J.; Leleux, P.; Ferro, M.; Ramuz, M.; Brendel, J. C.; Schmidt, M. M.; Thelakkat, M.; Malliaras, G. G., A High Transconductance Accumulation Mode Electrochemical Transistor. Adv. Mater. 2014, 26 (44), 7450-7455.

11. Inal, S.; Rivnay, J.; Suiu, A.-O.; Malliaras, G. G.; McCulloch, I., Conjugated Polymers in Bioelectronics. Acc. Chem. Res. 2018, $51(6), 1368-1376$.

12. Du, W.; Ohayon, D.; Combe, C.; Mottier, L.; Maria, I. P.; Ashraf, R. S.; Fiumelli, H.; Inal, S.; McCulloch, I., Improving the Compatibility of Diketopyrrolopyrrole Semiconducting Polymers for Biological Interfacing by Lysine Attachment. Chem. Mater. 2018, 30 (17), 6164-6172.

13. Giovannitti, A.; Sbircea, D.-T.; Inal, S.; Nielsen, C. B.; Bandiello, E.; Hanifi, D. A.; Sessolo, M.; Malliaras, G. G.; McCulloch, I.; Rivnay, J., Controlling the mode of operation of organic transistors through side-chain engineering. Proc. Natl. Acad. Sci. U.S.A 2016, $113(43), 12017-12022$.

14. Laiho, A.; Herlogsson, L.; Forchheimer, R.; Crispin, X.; Berggren, M., Controlling the dimensionality of charge transport in organic thin-film transistors. Proc. Natl. Acad. Sci. U.S.A 2011, 108 (37), 15069-15073. 
15. Rivnay, J.; Leleux, P.; Ferro, M.; Sessolo, M.; Williamson, A.; Koutsouras, D. A.; Khodagholy, D.; Ramuz, M.; Strakosas, X.; Owens, R. M.; Benar, C.; Badier, J.-M.; Bernard, C.; Malliaras, G. G., High-performance transistors for bioelectronics through tuning of channel thickness. Sci. Adv. 2015, 1 (4), e1400251.

16. Inal, S.; Malliaras, G. G.; Rivnay, J., Optical study of electrochromic moving fronts for the investigation of ion transport in conducting polymers. J. Mat. Chem.C 2016, 4 (18), 3942-3947.

17. Volkov, A. V.; Wijeratne, K.; Mitraka, E.; Ail, U.; Zhao, D.; Tybrandt, K.; Andreasen, J. W.; Berggren, M.; Crispin, X.; Zozoulenko, I. V., Understanding the Capacitance of PEDOT:PSS. Adv. Funct. Mater. 2017, 27 (28), 1700329.

18. Rivnay, J.; Inal, S.; Collins, B. A.; Sessolo, M.; Stavrinidou, E.; Strakosas, X.; Tassone, C.; Delongchamp, D. M.; Malliaras, G. G., Structural control of mixed ionic and electronic transport in conducting polymers. Nat. Commun. 2016, 7, 11287.

19. Savva, A.; Wustoni, S.; Inal, S., Ionic-to-electronic coupling efficiency in PEDOT:PSS films operated in aqueous electrolytes. $J$. Mat. Chem.C 2018, 6, 12023-12030.

20. Guardado, J. O.; Salleo, A., Structural Effects of Gating Poly(3-hexylthiophene) through an Ionic Liquid. Adv. Funct. Mater. 2017, 27 (32), 1701791.

21. Chew, A. R.; Salleo, A., Spectroscopic studies of dopant-induced conformational changes in poly(3-hexylthiophene) thin films. MRS Commun. 2017, 7 (3), 728-734.

22. Giridharagopal, R.; Flagg, L. Q.; Harrison, J. S.; Ziffer, M. E.; Onorato, J.; Luscombe, C. K.; Ginger, D. S., Electrochemical strain microscopy probes morphology-induced variations in ion uptake and performance in organic electrochemical transistors. Nat. Mater.2017, 16, 737.

23. Ohtaki, H.; Radnai, T., Structure and dynamics of hydrated ions. Chem. Rev. 1993, 93 (3), 1157-1204.

24. Flagg, L. Q.; Giridharagopal, R.; Guo, J.; Ginger, D. S., Anion-Dependent Doping and Charge Transport in Organic Electrochemical Transistors. Chem. Mater. 2018, 30 (15), 5380-5389.

25. Afanasiev, V. N.; Ustinov, A. N.; Vashurina, I. Y., State of Hydration Shells of Sodium Chloride in Aqueous Solutions in a Wide Concentration Range at 273.15-373.15 K. J. Phys. Chem. B 2009, 113 (1), 212-223.

26. Braendlein, M.; Lonjaret, T.; Leleux, P.; Badier, J.-M.; Malliaras, G. G., Voltage Amplifier Based on Organic Electrochemical Transistor. Adv. Science 2017, 4 (1), 1600247.

27. Bernards, D. A.; Malliaras, G. G., Steady-State and Transient Behavior of Organic Electrochemical Transistors. Adv. Funct. Mater. 2007, 17 (17), 3538-3544.

28. Rivnay, J.; Ramuz, M.; Leleux, P.; Hama, A.; Huerta, M.; Owens, R. M., Organic electrochemical transistors for cell-based impedance sensing. App. Phys. Lett. 2015, 106 (4), 043301.

29. Jan, I., Nika: software for two-dimensional data reduction. J. Appl. Crystallogr. 2012, 45 (2), 324-328.

30. Oosterhout, S. D.; Savikhin, V.; Zhang, J.; Zhang, Y.; Burgers, M. A.; Marder, S. R.; Bazan, G. C.; Toney, M. F., Mixing Behavior in Small Molecule:Fullerene Organic Photovoltaics. Chem. Mater. 2017, 29 (7), 3062-3069.

31. Rodahl, M.; Höök, F.; Krozer, A.; Brzezinski, P.; Kasemo, B., Quartz crystal microbalance setup for frequency and Q-factor measurements in gaseous and liquid environments. Rev. Sci. Instrum. 1995, 66 (7), 3924-3930.

32. Höök, F.; Rodahl, M.; Brzezinski, P.; Kasemo, B., Energy Dissipation Kinetics for Protein and Antibody-Antigen Adsorption under Shear Oscillation on a Quartz Crystal Microbalance. Langmuir 1998, 14 (4), 729-734.

33. Marcus, Y., Concentration Dependence of Ionic Hydration Numbers. J. Phys. Chem. B 2014, 118 (35), $10471-10476$.

34. Bay, L.; Jacobsen, T.; Skaarup, S.; West, K., Mechanism of Actuation in Conducting Polymers: Osmotic Expansion. $J$. Phys.Chem. B 2001, 105 (36), 8492-8497.

35. $\quad$ Maw, S.; Smela, E.; Yoshida, K.; Stein, R. B., Effects of monomer and electrolyte concentrations on actuation of PPy(DBS) bilayers. Synth. Metals 2005, 155 (1), 18-26.

36. Kawai, T.; Nakazono, M.; Sugimoto, R.-i.; Yoshino, K., Crystal Structure of Poly(3-alkylthiophene) and Its Doping Effect. J. Phys. Soc. Jpn 1992, 61 (9), 3400-3406.

37. Geise, G. M.; Paul, D. R.; Freeman, B. D., Fundamental water and salt transport properties of polymeric materials. Prog. Polym. Sci. 2014, 39 (1), 1-42.

38. Sainbileg, B.; Lan, Y.-B.; Wang, J.-K.; Hayashi, M., Deciphering Anomalous Raman Features of Regioregular Poly(3hexylthiophene) in Ordered Aggregation Form. J. Phys. Chem. C 2018, 122 (8), 4224-4231.

39. Francis, C.; Fazzi, D.; Grimm, S. B.; Paulus, F.; Beck, S.; Hillebrandt, S.; Pucci, A.; Zaumseil, J., Raman spectroscopy and microscopy of electrochemically and chemically doped high-mobility semiconducting polymers. Journ. Mater. Chem. C 2017, 5 (25), 6176-6184

40. $\quad$ Bruckmoser, K.; Resch, K.; Kisslinger, T.; Lucyshyn, T., Measurement of interdiffusion in polymeric materials by applying Raman spectroscopy. Polym. Test. 2015, 46, 122-133.

41. Milani, A.; Brambilla, L.; Del Zoppo, M.; Zerbi, G., Raman Dispersion and Intermolecular Interactions in Unsubstituted Thiophene Oligomers. Jour. Phys. Chem. B 2007, 111 (6), 1271-1276.

42. $\quad$ Lin, P.; Yan, F.; Chan, H. L. W., Ion-Sensitive Properties of Organic Electrochemical Transistors. ACS Appl. Mater. Interfaces 2010, 2 (6), 1637-1641 
Table of Contents artwork

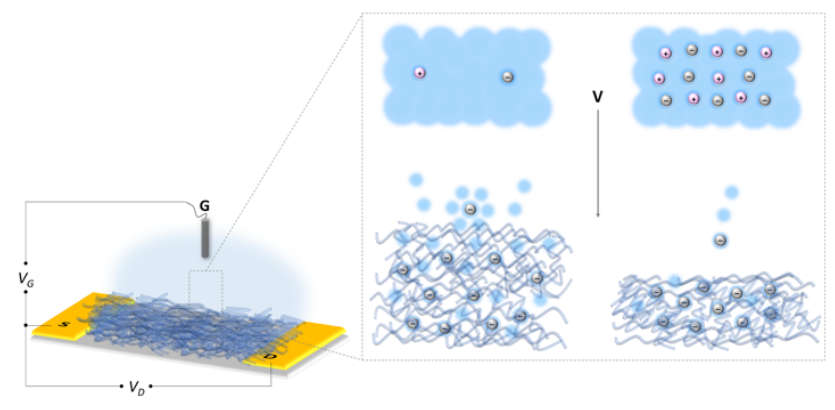

